\title{
LITEC: Laboratório de Inteligência e Tecnologias Educacionais em Computação
}

\author{
Ângelo Magno de Jesus ${ }^{1}$, Carlos Eduardo Paulino da Silva ${ }^{1}$, Lorena de Almeida da \\ Cunha Ferreira', Giovani Donizete Ambrósio \\ ${ }^{1}$ Instituto Federal de Minas Gerais Compus Ouro Branco (IFMG) \\ Ouro Branco - MG - Brasil \\ \{angelo.jesus, carlos.paulino\}@ifmg.edu.br, lorenacunha.if@gmail.com, \\ giovanidonizete@hotmail.com
}

\begin{abstract}
This paper presents the LITEC Research Group: Intelligence and Technologies in Computing Laboratory.
\end{abstract}

Resumo. Este artigo tem como objetivo apresentar o grupo LITEC: Laboratório de Inteligência e Tecnologias Educacionais em Computação.

\section{Objetivo do Grupo}

O LITEC é um grupo de pesquisa responsável por desenvolver novas tecnologias e metodologias para auxiliar o aprendizado em qualquer nível de ensino, seja básico, médio ou superior. O principal foco de pesquisa do grupo se encontra no projeto de jogos educativos eletrônicos e de robótica educacional.

\section{Instituições Envolvidas}

Atualmente o grupo de pesquisa envolve alunos e professores dos cursos de Licenciatura em Computação e Técnico Integrado em Informática do Instituto Federal de Minas Gerais (IFMG) campus Ouro Branco.

\section{Pesquisadores e Desenvolvedores}

Entre os pesquisadores envolvidos no LITEC, estão os professores Ângelo Magno de Jesus e Carlos Eduardo Paulino Silva, os alunos Lorena Ferreira, Fabiano Santos, Maria Caroline Rufo, Giovani Ambrósio e Dimas Gonçalves, Christian de Deus, Vinícius Viana e Douglas Santos.

\section{Projetos Desenvolvidos e em Andamento}

O grupo já desenvolveu alguns jogos eletrônicos, objetos de ensino "desplugados" e robôs programáveis para apoiar o ensino de Informática, outra vertente do grupo trabalha com a inclusão de mídias digitais em escolas públicas da região. Os projetos desenvolvidos e em andamento são: Desenvolvimento de um Robô Programado por Voz (apoiado pelo CNPQ), Desenvolvimento de um Drone Educacional (apoiado pelo IFMG e CAPES), Ambiente de Programação para Robótica Educacional, Metodologia de Desenvolvimento de Jogos Educacionais em Sala de Aula, Ketchup - Robô Comandado por Voz, Jogo Educacional I.T. Drama, Mídias Digitais na Educação (apoiado pela Capes via PIBID), Oficina de Scratch e Computação Desplugada. 